\title{
Documentando as aprendizagens experienciais da docência na/pela relação com estudantes
}

Fabrício Oliveira da Silva ${ }^{1}$

\begin{abstract}
Resumo
O relato de experiência emerge de uma prática desenvolvida no ensino de língua portuguesa na Educação Básica. Trata-se de uma experiência com ensino de conjunções desenvolvida em uma escola de ensino regular noturno da cidade de São Paulo. A metodologia ancorase nas bases epistemológicas da Documentação Narrativa de Experiências Pedagógicas, proposta por Suárez (2007). O dispositivo foi a escrita narrativa, produzida em primeira pessoa, por meio da qual a prática é ao mesmo tempo relatada e refletida, gerando a compreensão da produção de um saber experiencial. O trabalho possibilitou concluir que a aprendizagem experiencial da docência emerge das relações que o professor e os estudantes produzem no tensionamento do ensino que tecem no cotidiano escolar. Documentar a experiência facultou a reflexividade da prática, consagrando-a enquanto um saber experiencial que legitima as aprendizagens da docência que se tecem nas acontecências e nas necessidades de aprendizagem dos estudantes.
\end{abstract}

\section{Palavras-chave}

Aprendizagem experiencial. Docência. Documentação narrativa. Experiências Pedagógicas.

\footnotetext{
${ }^{1}$ Doutor em Educação e Contemporaneidade pela Universidade do Estado da Bahia, Brasil; estágio pós-doutoral na mesma instituição; professor adjunto do Departamento de Educação da Universidade Estadual de Feira de Santana, Bahia, Brasil; membro do Grupo de Pesquisa Docência, Narrativas e Diversidade na Educação Básica (DIVERSO); coordenador e membro do Núcleo de Estudos e Pesquisas sobre Pedagogia Universitária (NEPPU/UEFS). E-mail: fosilva@uefs.br.
} 


\title{
Documenting the experienced learning from teaching in/by relationship with students
}

Fabrício Oliveira da Silva ${ }^{2}$

\begin{abstract}
The experience report emerges from a practice developed in the teaching of Portuguese in Basic Education. It is an experience with conjunctions teaching developed at a regular night school in the city of São Paulo. The methodology is based on the epistemological bases of the Narrative Documentation of Pedagogical Experiences, proposed by Suárez (2007). The device was narrative writing, produced in the first person through which the practice is both reported and reflected, generating an understanding of the production of experiential knowledge. The work made it possible to conclude that the experiential learning of teaching emerges from the relationships that the teacher and the students produce in the tension of the teaching that they weave in the school routine. Documenting the experience provided the reflexivity of the practice, consecrating it as an experiential knowledge that legitimizes the teacher's learning that is woven into the events and the students' learning needs.
\end{abstract}

\section{Keywords}

Experiential learning. Teaching. Narrative documentation. Pedagogical Experiences.

\footnotetext{
${ }^{2} \mathrm{PhD}$ in Education and Contemporaneity, State University of Bahia, State of Bahia, Brazil; post-doctoral internship at the same institution; adjunct professor in the Department of Education at the State University of Feira de Santana, State of Bahia, Brazil; member of the Teaching, Narratives and Diversity in Basic Education Research Group (DIVERSO); coordinator and member of the Center for Studies and Research on University Pedagogy (NEPPU/UEFS). E-mail: fosilva@uefs.br.
} 


\section{Introdução}

A aprendizagem experiencial da docência, neste trabalho, emerge da compreensão de que os professores, em franco exercício da docência, aprendem, apreendem e desenvolvem saberes da profissão docente pelas relações homológicas que mantêm com os estudantes. A homologia, então, significa uma relação de aprendizagem dada pela vivência e convivência entre estudantes e professores, em que a ação de aprender não é unilateralizada. Isso implica, portanto, uma concepção de que a aprendizagem acontece na troca, na partilha, na abertura para perceber que ensinar não é mesmo, como nos diz Freire (1997, p. 32), "transferir conhecimento".

Entendo que o ensino não se constitui como uma mera transferência de conhecimento que o professor faz na relação pedagógica com o estudante. Há muitas ações em jogo, que se concretizam pela complexidade de processos mobilizados na ação de ensinar, visto que, para isso, o docente, por princípio fundante, deve produzir condições para que os estudantes mobilizem seus próprios saberes na perspectiva de construir outros novos. Trata-se de um processo caracterizado pelo desenvolvimento de compreensões de como uma aprendizagem se consolida, sobretudo quando se tem a noção de conhecer algo que não se sabia anteriormente.

Apesar de aparentar um processo simples, o ensino é uma atividade complexa, para a qual a formação nem sempre possibilita êxito. Ao se analisar os escritos de Gatti et al. (2019) e Gatti (2017), é possível entender que, no Brasil, há tempos, vem se discutindo o papel da formação de professores frente ao desafio de se poder exercer a profissão docente. A formação tem sido concebida como necessária e vital para que os professores possam desenvolver os processos de ensino.

É na formação de professores, sobretudo pelos aspectos visibilizados a partir da Lei de Diretrizes e Bases da Educação Nacional - LDB 9.394/96, com foco nas questões da prática educativa especificadas nas Diretrizes Curriculares Nacionais para a formação de professores DCN's 2/2002 (BRASIL, 2002), ampliadas e tecidas à luz das questões do cotidiano escolar e das necessidades de uma formação consolidada, também, na formação de práticas profissionais, pelas DCN's 02/2015 (BRASIL, 2015), que se assenta a grande problemática sobre a qual historicamente o país vem se debruçando.

Rev. Ed. Popular, Uberlândia, v. 20, n. 1, p. 233-250, jan.-abr. 2021. 
A formação, portanto, tem sido vital para que os professores na Educação Básica logrem êxito no processo de ensino que realizam. De fato, os processos formativos são essenciais e necessários para que o ensino gere aprendizagens significativas, tanto para professores quanto para estudantes. Se não há ideia de unilaterização no processo de ensino e aprendizagem, é fato que, tanto estudantes, como professores aprendem nessa relação. Assim sendo, o cotidiano passa a figurar como um espaço/tempo de aprendizagem em que alunos e professores logram saberes que lhes são úteis e significativos, o que, em alguns casos, ressignificam as aprendizagens tecidas na escola.

Tal concepção tem sido adotada enquanto um saber experiencial (SILVA; RIOS, 2018), um saber que emerge das singularidades dos processos de ensinar e de aprender, que se efetivam no cotidiano escolar, determinado por acontecências e por insurgências, que a formação de professores nem sempre possibilita aprender. São apreensões que ocorrem nas situações inesperadas, vivenciadas por professores e estudantes, que às vezes, colocam em xeque os modos de se relacionarem na sala de aula. De igual modo, são colocadas em xeque as práticas educativas que professores desenvolvem, muitas vezes aprendidas nos cursos de formação.

Quando certas situações como essas acontecem, os professores, em alguns momentos, ficam sem saber como lidar em determinada situação, sem saber como agir, pois, ao revistarem o seu repertório de saberes logrados na formação, não encontram ações efetivas que possam ser desenvolvidas naquele determinado momento. A sensação, portanto, tem sido de impotência, de fragilidade e de não visibilizar alternativas que não sejam a de sair de situações inesperadas. Mas é, exatamente, em momentos assim, que as aprendizagens experienciais se constituem e consolidam novos modos e práticas de ser e de atuar na profissão.

É no inesperado, no incerto, na provocação de um estudante, entre outras situações, que muitos professores constroem saberes da docência, e logram, quase que imediatamente, novas aprendizagens e novos resultados sobre o ensino que executam. Em momentos como este, o docente coloca em xeque a sua própria formação, percebendo que, apesar de ser necessária e vital, não foi pela formação que a aprendizagem, para aquele momento, se efetivou. O que faz gerar uma aprendizagem experiencial são as acontecências do momento vivido, são as situações inesperadas, mas que provocam nos professores grande possibilidade 
de realizar reflexões e entendimentos sobre como ele deve e pode agir em certas situações para lograr êxito no processo de ensino e aprendizagem que realiza.

De igual modo, as aprendizagens experienciais para os estudantes acontecem nessa relação com seus professores e na provocação, que muitas vezes é tecida, para produzir mobilizações de aprendizagens. Se ensinar não é transferir informações, a aprendizagem se fundamenta na mobilização para gerá-la, para produzir situações que promovam ações e consequentes reflexões originárias de tais ações. Assim sendo, a aprendizagem segue um ciclo que se efetiva num processo gerado por ação, provocação, reflexão, e nova ação, culminando em aprendizagens ambivalentes, o que favorece tanto a quem ensina, quanto a quem aprende.

É nessa esteira reflexiva que o presente relato de experiência se efetiva, como modo de partilhar com outros professores um exemplo de aprendizagem experiencial sobre o ensino de gramática que logrei ${ }^{3}$ em uma noite, numa aula que ministrava para estudantes da Educação Básica. Mais especificamente, tratou-se de uma aula sobre o emprego de conjunções em língua portuguesa, desenvolvida num contexto específico, tanto para os estudantes, como para mim, enquanto professor, que estava em franca formação em nível de pós-graduação, stricto sensu, na Universidade de São Paulo.

Dessa forma, o objetivo do presente trabalho é produzir um relato de experiência visibilizando a compreensão do modo como as aprendizagens experienciais emergem do cotidiano escolar e como elas podem ser documentadas e tornarem-se uma política de conhecimento de ensino para quem faz o próprio relato, bem como para tantos outros professores que vivenciam situações parecidas, mas não iguais, o que possibilita outros tantos modos de viver e de produzir aprendizagens experienciais do ser professor.

$\mathrm{O}$ relato se construiu a partir dos paradigmas da pesquisa qualitativa (MINAYO, 2012), que evoca o sujeito a produzir sentido para aquilo que faz e produz. Nessa perspectiva, a narrativa do relato em primeira pessoa aponta para uma narratividade fecunda, possibilitando transitar entre diferentes momentos da docência, em que se narra uma prática, e dela gera-se uma experiência. A produção do relato, portanto, segue os princípios da Documentação Narrativa de Experiências Pedagógicas, proposta por Suárez (2007). Trata-se

\footnotetext{
${ }^{3}$ Mantendo a coerência com a propositura do relato de experiência, sobretudo com a base epistemológica de documentar experiências pela metodologia adotada para a confecção do relato, escreverei em primeira pessoa, sobretudo na seção em que faço o relato da prática e da experiência.
} 
de um dispositivo de pesquisa, sobretudo, de produção narrativa de saberes e práticas que desenvolvem os professores no seio de sua profissão.

Na próxima seção, antes de produzir o relato da produção em tela, farei, ainda que suscintamente, uma apresentação discutindo a natureza epistemológica e metodológica da Documentação Narrativa de Experiências Pedagógicas.

\section{Tessituras metodológicas: a arte de documentar narrativamente as experiências pedagógicas}

A Documentação Narrativa de Experiências Pedagógicas centra-se nos fundamentos da ideia de que esse dispositivo não se encerra como uma mera técnica para coleta de informações, vivências e de experiências dos professores. Ao escrever o presente relato, fazendo-o nos fundamentos epistemológicos e metodológicos da Documentação Narrativa de Experiências Pedagógicas, tive a clareza de que estava documentando uma de muitas das minhas experiências como docente, logo lançando mão de um dispositivo que integra um relevante método de documentação de experiências pedagógicas da/na profissão docente. Nesse sentido, a ideia foi documentar uma de minhas experiências no ensino de língua portuguesa na escola básica, daí a ideia de tornar as experiências pedagógicas da docência como protagonistas do meu fazer docente, portanto reveladoras, das tessituras do fazer de um professor no cotidiano da profissão.

Esse movimento, como revela Suárez (2007), congrega a potencialidade de se constituir enquanto uma metodologia que gera uma política de conhecimentos advinda da experiência que os professores desenvolvem no exercício da profissão. Trata-se, portanto, de um método que prioriza o vivido, em que a narrativa se processa pelas vias das reflexões, problematizações, tematizações e constituições de saberes do cotidiano que se emancipam e tornam-se grandes referências para se pensar a profissão docente em suas dimensões formativas e de processos de profissionalização.

Assim, a Documentação Narrativa de Experiências Pedagógicas caracteriza-se como qualitativa a partir de princípios que tornam publicáveis, em documentos, as experiências pedagógicas que professores produzem a partir de aprendizagens experienciais que logram no cotidiano da profissão. As bases teórico-metodológicas da Documentação Narrativa de Experiências Pedagógicas são fundamentadas pelos trabalhos desenvolvidos por Daniel Rev. Ed. Popular, Uberlândia, v. 20, n. 1, p. 233-250, jan.-abr. 2021. 
Suárez (2007) por meio do Programa de Documentação Pedagógica e Memória do Laboratório de Políticas Públicas de Buenos Aires (UBA) que nos mostra que:

A relevância que adquire a documentação narrativa das próprias experiências escolares dos professores reside no enorme potencial que essas histórias pedagógicas contêm para ensinarmos a interpretar o mundo escolar do ponto de vista dos seus protagonistas. Desse modo, ao tecer suas narrativas, os professores nos comunicam sua sabedoria prática e, ao mesmo tempo, permitem que outros as desvendem para explicitar o implícito e compreender o que está por trás dessa sabedoria. Ou seja, a narrativa estrutura a experiência, e as histórias são uma forma de conhecê-la, refleti-la, transmitila e compartilhá-la com os outros. (SUÁREZ, 2007, p. 16, tradução nossa ${ }^{4}$ ).

A documentação narrativa nasce na Argentina, no âmbito das políticas educacionais articuladas ao próprio Ministério da Educação, Ciência e Tecnologia. Todavia, surge como uma alternativa formativa aos modelos heterodoxos de formação, buscando valorizar, legitimar e tornar públicas experiências, saberes e processos pedagógicos vividos no cotidiano das escolas.

Em experiências vividas por alguns grupos de pesquisa, tais como o Docência, Narrativas e Diversidade na Educação Básica (Diverso), do Programa de Pós-Graduação em Educação e Contemporaneidade (PPGEduC), da Universidade do Estado da Bahia (UNEB), e o Grupo de Estudos e Pesquisa das Professoras Alfabetizadoras, Narradoras (Geppan), do Programa de Pós-Graduação em Educação (PPGE), da Universidade Federal Fluminense (UFF), coletivos de docentes têm se reunido para estudarem e documentarem suas experiências pedagógicas, produzindo um momento duplo, de formação e, ao mesmo tempo, de produção de saberes que emergem das experiências de professores que atuam na Educação Básica. Tais grupos concluem que a documentação também aposta nessa valorização, legitimação e publicização de experiências e saberes docentes.

No âmbito do grupo de pesquisa Diverso, Oliveira (2019) produziu a tese intitulada "Viagem-formação: documentação narrativa de experiências pedagógicas de professores(as)

\footnotetext{
${ }^{4}$ La relevancia que adquiere la documentación narrativa de las propias experiencias escolares por parte de los docentes radica en el enorme potencial que contienen estos relatos pedagógicos, para enseñarnos a interpretar el mundo escolar desde el punto de vista de sus protagonistas. De esta manera, al tejer sus narraciones, los docentes nos comunican su sabiduría práctica y, al mismo tiempo, permiten a otros destejerlas para volver explícito lo implícito y comprender qué hay detrás de esa sabiduría. Es decir, la narrativa estructura la experiencia, y los relatos son una forma de conocerla, reflexionar sobre ella, trasmitirla y compartirla con otros. (SUÁREZ, 2007, p. 16).
} 
no ensino médio de escolas rurais". O autor se vale da documentação narrativa como método para a construção de políticas de conhecimentos em torno das experiências formativas de professores a partir das práticas educativas cotidianas que eles realizam no seio da profissão docente. Trata-se da primeira tese produzida e defendida na Bahia que institui a Documentação Narrativa de Experiências Pedagógicas como método de produção de conhecimentos do fazer educativo, gerando publicações das narrativas dos professores colaboradores, o que consagra o princípio de autoria da própria prática.

As discussões feitas acerca das investigações com documentação narrativa revelam modos próprios e fecundos de compreensões teórico-metodológicos das experiências educativas como dispositivo de investigação-formação que potencializam a memória e as experiências dos docentes. Assim, compreendo que a produção da documentação narrativa estabelece o encontro hermenêutico do sujeito com o seu vivido, não como um acúmulo de vivências, mas como movimento reflexivo de constituir práticas em saber. Essa opção metodológica delineia-se, também, como uma prática formativa em que as experiências pedagógicas do coletivo são tomadas como dispositivos de investigação-ação-formação, revelando o fazer cotidiano da docência nas diferentes temporalidades que compõem a narrativa.

\section{Documentando a experiência}

O movimento inicial dessa escrita me provocou a pensar sobre a grande questão que me move na docência. Ser professor não foi uma escolha muito fácil em minha vida, embora sempre tenha ocupado o lugar de certeza e convicção. Sou professor por escolha e por vontade própria de querer fazer o que gosto e o que me enche de alegria e satisfação. A relação com os vários estudantes que tive ao longo da vida me provocou sensações de muito crescimento intelectual, espiritual e, sobretudo, humano. Foram situações, práticas e vivências que se transformaram em grandes experiências do ser educador. Cabe, já aqui, esclarecer que a experiência não significa, necessariamente, um saber aperfeiçoado da docência, mas significa um saber que se constituiu pelos acontecimentos que me tocaram, que aconteceram comigo, que me moveram e me deslocaram a caminhos outros de reflexão e de (re)construção do fazer pedagógico. Dito isso, tenho a convicção de que chegar até aqui não foi nada fácil, 
mas foi fruto de muita motivação pessoal e de vontade se superação, recheada de leveza e de alegria.

Acredito que a formação inicial foi uma determinante para a minha chegada à profissão docente, mas as experiências logradas na docência foram determinantes para a minha permanência e crescimento na profissão de professor. Os vários desafios vividos me levaram a perceber que esse era um caminho possível e viável para tornar-me uma pessoa melhor e com condições de melhorar a vida do outro, nesse caso, a dos meus alunos. Assim, ser professor se concretizou em minha história de vida e de atuação profissional pela possibilidade de manter-me em perene condição de reflexão e de relação com o outro. Esse, portanto, foi o caminho que percorri para chegar a compreender como as práticas com a docência foram se insurgindo e gerando em mim experiências, que se tornam a cada dia elementos fundantes das ações que venho desenvolvendo no percurso profissional. Assim, a experiência é, mesmo, como diz Bondía (2002), o que me acontece, o que me toca, o que me move a produzir saberes e práticas ancoradas nas ideias e fundamentos que desenvolvo para constituir-me docente.

No âmbito da docência, os diálogos com os estudantes tornaram-se cada vez mais possíveis. Abriram espaço e condições para a construção de conhecimentos, saberes e práticas que marcaram o meu modo de ser, e, de alguma maneira, o modo de ser dos estudantes com quem convivi ao longo desses vinte anos de magistério que completo em minha vida. Foram construções de saberes e práticas educativas deixaram marcas no meu modo de ser, de viver e de pensar as estratégias para desenvolver a atuação docente, sobretudo no campo do ensino de língua.

Os diálogos com os estudantes foram sendo cada vez mais realísticos e trazendo para as aulas a necessidade do cotidiano de cada um deles. Foi necessário repensar muitas ações, sobretudo considerando as necessidades formativas dos estudantes. O contexto da escola, da sala, e, sobretudo, o contexto de vida e a necessidade do próprio estudante, passaram a fazer mais sentidos nas minhas aulas e principalmente no planejamento de cada uma delas. Sou professor de língua portuguesa, por escolha da profissão, mas também porque sempre gostei de ler e de escrever e de estudar nossa língua. Também, eu sempre achei muito chique falar bem e saber as questões gramaticais. Até então, eu pensava que ensinar português significava ensinar gramática. 
No contexto de minha atuação profissional, reconheço-me sujeito da/na ação formativa, pois que me faço e refaço nos percursos da docência, logo de minha própria caminhada na ação educacional. Ser e estar do/no mundo da docência implica uma motivação consciente para perceber-me um professor culturalmente constituído pelas relações que estabeleço no mundo da docência e comigo mesmo. É desse lugar que inicio a escrita desse relato, inspirado na concepção de relações produzidas na minha história de vida, em particular é uma específica história de atuação profissional, que elejo para partilhar com os colegas.

Isso posto, digo que muitas experiências atravessam a minha história na profissão docente, constituindo-me enquanto sujeito da própria experiência, condição que me torna, a cada dia, alguém que se afeta pela constante motivação e movimentação do ser estudante, professor e pesquisador, vivendo a expectativa de entender a si mesmo e aos outros com quem estabeleço relações na minha profissão. Assim, meu processo identitário e de aprendizagem experiencial está em contínua ebulição, fazendo-se e refazendo-se nas/pelas experiências cotidianas de ser docente, na multiplicidade de ações e situações que produzem em mim mesmo a consciência de ser o sujeito de minha própria história de formação e de atuação profissional, história que é, sobretudo, marcada pela relação com o outro.

Em minha travessia pela docência, encontrei várias situações, vivências e experiências que me fizeram pôr em constante atividade a reflexão sobre mim, principalmente, a respeito do estudante e do que as minhas ações pedagógicas no âmbito da sala de aula provocariam nele. Nem sempre foi assim, reconheço, mas foi sobre uma experiência, em particular, que percebi que o impacto aconteceu em via contrária, posto ter sido uma ação específica, dentre tantas que já me aconteceram na docência, provocada por um estudante, que impactou em mim de modo a provocar significativas mudanças na forma como eu via, entendia e ensinava língua portuguesa na escola básica.

Nesse contexto, demarcando a tessitura de uma prática que me possibilitou muitas reflexões e ponderações, elejo uma experiência vivida por mim no ano de 2002, numa escola da rede municipal de São Paulo, na qual eu era professor efetivo de língua portuguesa, com atuação na Educação de Jovens e Adultos (EJA). Esse foi o meu primeiro ano na escola, recém-concursado pela Prefeitura Municipal de São Paulo, na condição de professor titular que, conforme a carreira docente na época, era o nível mais elevado de categoria salarial. Só por isso, eu já me sentia o todo poderoso da escola. Somava-se a isso, a minha empáfia de me sentir o grande professor de língua materna, por estar fazendo mestrado no Programa de PósRev. Ed. Popular, Uberlândia, v. 20, n. 1, p. 233-250, jan.-abr. 2021. 
Graduação em Filologia e Língua Portuguesa da Universidade de São Paulo (USP). Na escola intitulada EMEF Jardim Vila Nova, eu trabalhava com três turmas de EJA, do Eixo II. Eram turmas compostas por alunos que cursavam as antigas $7^{\mathrm{a}}$ e $8^{\mathrm{a}}$ séries. Em sua maioria, adultos, e os mais novos com a idade mínima de dezoito anos.

Era meado do mês de abril, quando eu tomei posse na escola e vou a minha primeira aula na turma 2 da $7^{\mathrm{a}} / 8^{\mathrm{a}}$ séries da EJA. Era um grupo composto de mais ou menos vinte e cinco estudantes, em sua maioria senhoras, e alguns senhores também, que trabalhavam como diaristas, pedreiros, pintores, carpinteiros etc., e uns jovens que vendiam doces nos ônibus e metrôs da cidade. Naquele fatídico dia, a minha primeira aula na escola começou às dezenove horas e seriam duas aulas geminadas, com duração de quarenta minutos cada. Pois bem, eu todo cheio das teorias linguísticas, e sem conhecer qual o perfil da turma, preparei uma aula sobre conjunções. Assim, montei todo o esquema para apresentar aos estudantes o conceito, classificação e as caracterizações das conjunções coordenativas, utilizando, como exemplo, os textos clássicos das literaturas brasileira e portuguesa.

Inicio a aula, dando boa noite, falando meu nome, dizendo quem eu sou e despejando nos estudantes a minha condição formativa, sobretudo de ser mestrando da maior universidade do país. Sentia-me o grande professor naquela escola, que, por característica, era feita com material de zinco. Era uma escola que se situava na zona leste da capital, no interior de uma ocupação que fica no bairro de Itaquera. Até então eu não conhecia nada da comunidade e nem daquela escola, que eu achava feia demais, pois era um contêiner armado com telhados de zinco que faziam um barulho infernal quando chovia e um calor mortal quando o sol esquentava. Esse tipo de escola foi produzido pela prefeitura de São Paulo em comunidades carentes e era conhecido como as famosas escolas de lata da gestão do exprefeito Celso Pita.

Logo após os ritos iniciais da aula, volto para o quadro negro e começo a escrever pontos da aula. Vou priorizando os textos clássicos, cultos, a norma padrão, a gramática normativa como elemento fundante da boa aula de português. Nesse ínterim, tanto falo, quanto escrevo frases complexas, esdrúxulas, falando sobre o que eram as conjunções aditivas, adversativas, conclusivas, alternativas e as explicativas. Esforçava-me para dar os exemplos mais difíceis, como modo de mostrar a minha "sapiência" para aqueles estudantes, que não falavam nada e se mantinham em completo silêncio. Talvez eles tivessem diante de um alienígena, alguém que não era mesmo do mundo deles. E de fato, eles estavam sim. Até Rev. Ed. Popular, Uberlândia, v. 20, n. 1, p. 233-250, jan.-abr. 2021. 
que um jovem, de dezenove anos, morador da comunidade, vendedor de doces no metrô, indignado com aquela situação vexatória para ele e para os colegas, levanta-se no meio da sala, no exato momento em que me viro para eles para perguntar se estavam entendendo o que eu explicava, e diz bem alto e em bom tom ${ }^{5}$ :

Fessor, cê é maluco mê irmão. Cê tá tirano nóis aqui véi. Chega aí todo falano esses negócio qui agente nun intendi nada, com essa cara de retardado, todo quereno se mostrar prá nóis aqui, com essa conversa imbolada de cunjunção de diversativa, de aditiva. Ninguém quer saber sesse bagui aqui não, véi. Pare de falar esse negócio aqui, pois a treta vai ficar feia pro seu lado viu. Eu aqui quero sabê como vou ficar bom da guinorréia que tá me doendo e cê vem encher o saco com essa coisa aí qui ninguém tá entendendo não. Pô pará, que nóis num vai ficar aqui ôvindo essas bestages não véi. [...]. (Estudante, relato oral, 2002).

Enquanto o estudante falava, todos os outros acenavam em aprovação, posicionandose ao lado dele, reprovando toda a minha aula e o meu trabalho educativo ali. Naquele momento, me senti um rato, um pequeno inseto, que merecia mesmo ser esmagado. O tempo em que o estudante ficou me falando tudo aquilo foi o tempo de infinita magnitude, pois parecia que ele falava por mil anos, o tempo não passava, e a angústia me invadia o peito. Passava um mundo de coisas em minha cabeça e eu não sabia o que fazer. Aí, me veio uma coisa em mente, que em toda a minha formação eu não tinha aprendido, mas naqueles segundos eu aprendi. Encorajei-me, olhei fundo no olho do estudante, e disse a ele:

Mano, cê é loco, cê num entendeu a bagaça aqui não?!?!. Mano se liga na parada, aqui, o baguio é firmeza. Vê só maluco. Essa treta aqui é para tu aprender a ligar as paradas, entende?, pra tu explicar o negócio véi. Pra tu sabê também que tu pode concluir, mê irmão, tuas idea. Vê só como é simples a parada aqui. Spia como tu faz [...].

$\mathrm{Na}$ verdade, eu não sabia o que fazer naquele momento e precisava mesmo encontrar uma estratégia para sair daquela situação constrangedora de não saber o que falar para que ele entendesse o papel de um professor de língua portuguesa. Assim sendo, o que me ocorreu foi tentar mapear todas as palavras que ele falava enquanto colocava em xeque a minha prática

\footnotetext{
${ }^{5}$ Cabe informar que o registro foi feito por mim logo após ter concluído a aula, como forma de mapear o que o estudante tinha dito. Busquei escrever tal qual o estudante tinha falado, inclusive registrando os aspectos de sua oralidade.
} 
pedagógica de transmitir os conhecimentos gramaticais sobre conjunção. Dito e feito, observei a oralidade, as expressões, a empostação de voz, a entonação, o ritmo e a tessitura das palavras que ele usava e tentei usar a mesma linguagem com ele, garantindo que eu pudesse me comunicar efetivamente e ganhar dele confiança. No ímpeto de continuar garantindo uma comunicação em mesmo tom linguístico, viro para o quadro, apago rapidamente o que estava registrado e volto a escrever e a falar exemplos assim:

Estou com guinorréia mas vou achar uma cura. Eu tenho guinorréia porque não me cuidei com as mina. Ou eu trato minha guinorréia ou vou ficar doente. Eu tretei com as mina sem usar camisinha por isso estou com guinorréia [...] Mano. Cê não entendeu, mano!?, o negócio é pra tu saber como arrumar as frase aqui. Mano. Tu tem que saber que tu pode ligar uma ideia a outra, juntar o negócio, como um mais um é dois. Tu pode botar o negócio diferente, os contrário, se ligou? Assim tu vai as vezes dizê qui tu tretou com a mina, qui tu se cuidô, mas que tu mesmo assim pegô guinorréia mano.

E assim eu continuei a trazer exemplos, a mostrar como as conjunções estão na base da produção de frases que eles usam no dia a dia deles. Nesse momento, a turma caiu na risada e alguns estudantes ficaram dizendo que: "ó só o baiano tirado, óia, fala qui nem nóis. Aí sim, fessô, agora dô valô, agora o baguio tá na linha”. E começaram a me perguntar sobre isso, a querer que eu ajudasse a montar frases para colocarem em placas que usavam no serviço em oficinas. As meninas queriam aprender a usar isso num bilhete para mostrarem as patroas que sabiam usar bem as ideias.

A partir desse momento, senti que rasguei toda a minha formação e passei a trabalhar na perspectiva dialógica com os estudantes. Todo o estudo sobre variação linguística tinha ido por terra, pois o que me salvou naquele momento foi a sagacidade de aprender rapidamente, enquanto eu era atacado, a usar a mesma língua do sujeito e a me inserir na realidade dele. A partir daí, eles faziam tudo que eu propunha e passei a ensinar leitura e escrita, considerando potencializar a necessidade de comunicação efetiva dos estudantes, elegendo conteúdos gramaticais e linguísticos a partir do uso que faziam em seu dia a dia, bem como de algumas dificuldades que eles revelavam. Continuei ensinando língua portuguesa, mas numa perspectiva que se produzia no cotidiano escolar, no chão da sala de aula, no que me tocava e me movia a ensinar algo que fosse produtivo para eles e daí então mostrar a norma padrão e o lugar dela na vida dos estudantes. 
A experiência da prática me levou a considerar a contribuição de Paulo Freire para entender que ensinar não é transmitir conhecimento, mas poder mobilizar o outro para aprender. Intuitivamente eu acabei por desenvolver ações educativas que se aproximavam daquilo que Freire defendia no tocante aos saberes da docência. O cotidiano da escola e a realidade dos meus alunos passaram a ser a minha maior faculdade, a maior lição de vida para que eu pudesse repensar as questões centrais do ensino de língua materna a partir do contexto de uso e de necessidade reflexiva, para que o ensino pudesse ter um sentido na vida dos estudantes. Aprendi, com essa experiência, que muitas lições, presentes nos referenciais sobre o ensino de português na escola, deviam nascer das aprendizagens experienciais na interação com os estudantes.

De algum modo, a frustração da prática tradicional para o ensino de conjunções transformou-se em uma experiência que emergiu da condição reflexiva que obtive no transcurso da aula para desenvolver novos saberes sobre o ensino de gramática na escola. Isso significa, para mim, perceber que a prática docente não se encerra em si mesma quando sobre ela ocorre algo que nos toca, que nos move e que nos transforma pela reflexão que somos obrigados a fazer, por estarmos inseridos no ambiente de aprendizagem responsável pela produção da própria prática, que, ao se constituir por uma base dialógica, abre espaço para a produção de saberes que vão se delineando pela política de conhecimento que se instaura no professor a partir das reflexões que se produzem ciclicamente nesse movimento.

Com essa experiência, passei a repensar meu papel como professor de língua materna, e a considerar a necessidade de ouvir os estudantes, conquistá-los primeiro e, só então, produzir algo que seja significativo para a realidade de cada um.

Ao revistar essa prática, percebo que ela deu espaço para que as aprendizagens sobre o ensino de língua, ancoradas nas necessidades comunicativas dos estudantes, se efetivassem como uma política válida para mim mesmo a respeito do papel do professor de língua portuguesa. Assim, o ensinar se desloca da ideia de mera transmissão de conhecimento para gerar possibilidade reflexiva com os estudantes, para pensar o papel das conjunções no contexto da produção das enunciações, das produções discursivas que transcendem um registro formal linguístico. Pensar por esse viés implica reconhecer que a docência vai se constituindo para além das formações que realizamos nos cursos e na produção de conhecimentos na Universidade. Ela, de fato, se constitui no movimento experiencial do chão 
da escola, a partir das acontecências e das emergências que são tecidas na relação com os estudantes, sobretudo nas necessidades educativas que essa relação vai gerando.

De algum modo, a minha prática, inicialmente não exitosa, torna-se o ponto de reflexão para que eu, de fato, entenda o que já dizia Freire (1997) ao considerar que ensinar não é transferir conhecimento. Eu não tinha como, no contexto das realidades educacionais daquela turma, transferir qualquer conhecimento sobre conjunções, ou sobre qualquer outro conteúdo, se eu não estivesse disposto a mobilizar os estudantes a produzirem conhecimento, considerando os seus contextos próprios de vida e de escolarização. Foram os estudantes que me ensinaram, durante uma aula, a respeitar o que Bortoni-Ricardo (2005) defende sobre a necessidade de trabalharmos na perspectiva da variação linguística, considerando, sobretudo, a necessidade e o modo como os professores trabalham com as variações da língua em sala de aula.

Além disso, a aula que os estudantes me deram significou (re)pensar o meu posicionamento educativo frente aos objetivos do ensino que eu apresentava a mim mesmo, mas que pouco entendia. Ser tocado pela experiência gerou em mim a condição de ser tocado pela acontecência da prática que eu desenvolvia para gerar novos saberes e novas formas de lidar com as questões didático-metodológicas, produzindo estratégias sobre o processo de ensino, com vistas a garantir a aprendizagem pela relação com o outro e a partir da necessidade do próprio estudante.

A sala de aula, lócus privilegiado da produção de práticas pedagógicas, tornou-se palco da produção de práticas educativas, que, no contexto da situação nesse texto relatada, transcendem a paradigmas conteudistas do ensino de língua pelo viés tradicional. As práticas educativas se insurgiram como movimentos dialógicos e reflexivos na relação com os estudantes, considerando os acontecimentos que tocaram os estudantes, mas a mim também, gerando a experiência educativa, como algo que acontece com alguém de modo singular, que o modifica e que o transforma. É nessas travessias que as políticas de conhecimento vão se tecendo pelas acontecências da sala de aula, do cotidiano escolar e da reflexão que se produz no céu da docência e no chão da sala de aula.

\section{Considerações}


Ao documentar narrativamente uma de minhas experiências na docência de língua portuguesa, percebo que o próprio momento e o movimento de escrita do relato foram me provocando reflexões sobre esse fazer, ancorado numa perspectiva de docência que se insurge na ação, provocação, reflexão e em nova ação. Esse ciclo valida o processo de que a aprendizagem da docência se efetiva, também, no cotidiano da profissão, gerando novos saberes e novas práticas. Ademais, o movimento de documentar a experiência, que passa por sucessivas escritas e reescritas, até se chegar à ideia de que uma prática gera uma experiência, produz saber que se legitima na tessitura reflexiva proporcionada pelo ato de narrar.

Nessa direção, o ensino de gramática, que eu realizava até então, foi ressignificado pelo tensionamento que o estudante provocou ao manifestar suas reais necessidades educativas diante de uma situação que ele estava vivenciando. Não se tratou de produzir uma reflexão do ensino a partir de situações singulares e particulares do estudante. Na verdade, a partir da provocação que ele fez, e da manifestação linguística de uma variedade de que ele fazia uso, encontrei estratégias dialógicas para produzir sentido não só para um estudante em particular, mas também para todos os demais. Isso gerou, tanto para mim, como para os estudantes, aprendizagens experienciais. No meu caso, no que tange ao ensino de conjunções, no deles, da necessidade de estudar a linguagem a partir de uma funcionalidade ressignificada pelas tensionamentos do próprio cotidiano em que cada estudante vivia.

O relato de experiência possibilitou, ainda, compreender que uma prática e uma experiência são coisas diferentes. Enquanto a prática está voltada para a operacionalização de um saber, a experiência revela a produção do próprio saber, pelos acontecimentos que tocam o sujeito que produz experiência. Nessa lógica, de uma prática chega-se à experiência. Isso é possível quando a prática possibilita abertura para produção de tensionamentos e reflexões que o professor desenvolve ao realizar o próprio fazer docente.

Trata-se, portanto, de compreender que uma experiência não gera um saber acumulado pelo tempo de trabalho ou pelo desenvolvimento de uma prática muitas vezes. São as singularidades e as tessituras da prática que deslocam o sujeito para refletir outras possibilidades do seu fazer, gerando disposição para tornar sua ação educativa uma política de conhecimento tanto para si próprio quanto para outros. Essa é a razão pela qual a Documentação Narrativa de Experiências Pedagógicas favoreceu, no caso do relato em tela, a possibilidade de documentar uma prática particular de ensino, que gerou uma aprendizagem experiencial da docência, não lograda, no contexto evidenciado, nas travessias formativas Rev. Ed. Popular, Uberlândia, v. 20, n. 1, p. 233-250, jan.-abr. 2021. 
pelas quais passei ao longo da formação acadêmica. O jeito peculiar de ensinar conjunções, a tessitura do trato com os estudantes e a necessidade de tornar a aprendizagem significativa foram produzidos nas acontecências da profissão docente, logo, no cotidiano escolar.

\section{Referências}

BONDÍA, J. L. Notas sobre a experiência e o saber de experiência. Rev. Bras. Educ. Rio de Janeiro, n.19, p. 20-28, abr. 2002. Doi: 10.1590/S1413-24782002000100003. Disponível em: https://www.scielo.br/j/rbedu/a/Ycc5QDzZKcYVspCNspZVDxC/abstract/?lang=pt. Acesso em: 15 maio 2020.

BORTONI-RICARDO, S. M. Nós cheguemos na escola, e agora?: sociolinguística \& educação. São Paulo: Parábola Editorial, 2005.

BRASIL. Ministério da Educação. Conselho Nacional de Educação. Resolução CNE/CP no 1 de 18 de fevereiro de 2002. Institui as Diretrizes Curriculares Nacionais para a Formação de Professores da Educação Básica, em nível superior, curso de licenciatura, de graduação plena. Disponível em: http://portal.mec.gov.br/cne/arquivos/pdf/rcp01_02.pdf Acesso em: 22 maio 2020.

BRASIL. Conselho Nacional de Educação. Conselho Pleno. Parecer no 2/2015. Diretrizes Curriculares Nacionais para a Formação Inicial e Continuada dos Profissionais do Magistério da Educação Básica. Brasília: CNE, 2015.

FREIRE, P. Pedagogia da autonomia. São Paulo: Editora Paz e Terra, 1997.

GATTI, B. A. Formação de professores, complexidade e trabalho docente. Rev. Diálogo Educ., Curitiba, v. 17, n. 53, p. 721-737, 2017. Doi: 10.7213/1981-416X.17.052.AO01. Disponível em: https://periodicos.pucpr.br/index.php/dialogoeducacional/article/view/9822. Acesso em: 18 maio 2020.

GATTI, B. A. et al. Professores do Brasil: novos cenários de formação. Brasília: UNESCO, 2019.

MINAYO, M. C. S. Análise qualitativa: teoria, passos e fidedignidade. Ciênc. saúde coletiva, v. 17, n. 3, p. 621-626, mar. 2012. Doi: /10.1590/S1413-81232012000300007. Disponível em: https://www.scielo.br/j/csc/a/39YW8sMQhNzG5NmpGBtNMFf/?lang=pt. Acesso em: 18 maio 2020.

OLIVEIRA, A. D. Viagem-formação: documentação narrativa de experiências pedagógicas de professores (as) no ensino médio de escolas rurais. 2019. 199 f. Tese (Doutorado em Educação) - Universidade do Estado da Bahia, Salvador, 2019. 
SILVA. F. O.; RIOS, J.A.V. P. Aprendizagem experiencial da iniciação à docência no PIBID. Práxis Educativa, Ponta Grossa, v. 13, n. 1, p. 202-218, jan./abr. 2018. Doi: 10.5212/PraxEduc.v.13i1.0012. Disponível em:

http://www.revistas2.uepg.br/index.php/praxiseducativ. Acesso em: 16 maio 2020.

SUÁREZ, D. H. Docentes, narrativa e investigación educativa: la documentación narrativa de las practicas docentes y la indagación pedagógica del mundo y las experiencias escolares. In: SVERDLICK, I. et al. La investigación educativa: una herramienta de conocimiento y de acción. Buenos Aires: Noveduc, 2007. p. 8-27.

Submetido em 26 de maio de 2020.

Aprovado em 17 de agosto de 2020. 